\title{
The Specification of Observed COVID-19 in England: A Review of Auto-Mutation
}

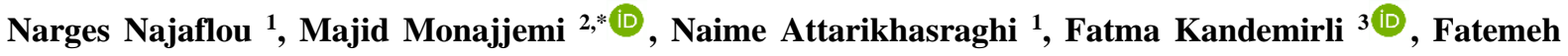 \\ Mollaamin 2 (i) \\ Department of Chemistry, Science and Research Branch, Islamic Azad University, Tehran, Iran \\ Department of Chemical engineering, Central Tehran Branch, Islamic Azad University, Tehran, Iran \\ Department of Biomedical Engineering, Faculty of Engineering and Architecture, Kastamonu University, Kastamonu, \\ Turkey \\ * Correspondence: m_monajjemi@srbiau.ac.ir; maj.monajjemi@iauctb.ac.ir (M.M.);
}

Scopus Author ID 670181068

Received: 3.02.2021; Revised: 1.03.2021; Accepted: 3.03.2021; Published: 31.03.2021

\begin{abstract}
Genomic sequencing helps us understand COVID-19 and its spread. It can also help guide treatments in the future and see the impact of interventions. In epidemics, genome structure is important for recognizing any small change in the COVID-19 behavior at any population scale to understand the spreading mechanism and whether different strains are emerging. The viral spike (S) protein amino acid sequence viral genomic sequences and other mutated spike proteins are related to the advanced genome of mRNA We analyzed some major S protein mutation which was represented in a high percentage of all the analyzed sequences. Spike-D614G mutation is a terrible phenomenon that has been spread in Europe in early February and has been started rapidly to become the dominant form in new regions. In the United States, the genotypic distribution in California and Washington was similar to Asian countries, while other US states' distribution was comparable to Europe. To gain insight into the D614G mutation consequences, homology modeling using a multi-template threading mechanism with ab initio structural refinement was performed for the S protein region. The D614 model predicted a random coil structure in the Furin domain, and this mutation may confer a competitive advantage at the Furin binding domain that may contribute to the rise of the D614G virus mutant. Due to resistance to any pandemic interventions, mutations should be evaluated in viewpoints of time and geographical situation in the wide phylogenetic domains to announce an early warning system for new mutations.
\end{abstract}

Keywords COVID-19; spike protein; COVID-19 mutation; England Coronavirus; evolutionary footprint in spike.

(C) 2021 by the authors. This article is an open-access article distributed under the terms and conditions of the Creative Commons Attribution (CC BY) license (https://creativecommons.org/licenses/by/4.0/).

\section{Introduction}

By two decades[1-7], three main pathogenic of $\beta$-Coronaviruses have been recognized. The first one is SARS in 2002 [1,2,7], which infected over 10,000 people and killed 1000, and the second was followed in 2012 by Middle East Respiratory Syndrome, and the last one is COVID-19. The COVID-19 was reported in China in December 2019 [8-12] and triggered an epidemic that quickly spread globally to become a pandemic in our world. Over 90 million confirmed cases of COVID-19 and over 1.8 million deaths have been reported by World Health Organization (WHO) [13-16]. A few major reasons make this disease dangerous, including no direct immunological experience and highly transmissible potential, leaving us vulnerable to infection $[17,18]$. Several important functions make this virus dangerous that can be mentioned as: 1- humans have not been any previous immunological experience with this virus. 2- It is 
completely, transmissible and also has a large mortality rank. 3- Evaluates of reproductive ratio, "R0", has a wide yield, but generally range exhibit a range among 2.0-4.0 [17,19]. Calculating deaths per each certain case also is difficult, but there is a range among $1 \%-15 \%$ percentages. These differences are based on test access in each place[20,21]. An active variant of the corona pandemic is spread in the whole of London. Researchers found it is considerably more contagious than other types $[21,22]$ and has been made some limitations in the flight within Europe[23]. British Prime Minister declared that the new type of the virus is $75 \%$ faster transmissible than the COVID-19 and seems to be driving a sharper spike in new infections in many places of London.

England's health secretary [24,25], Matt Hancock, has told parliament members that a new variant of COVID-19 has been identified and may be driving infections in the south east of England, leading to headlines about "mutant" virus [26]. VUI-202012/01 has been known completely and also has been classified by sixteen mutations. One of the most scientific applications is an N501Y mutation in the spike protein that the virus uses to bind to the human ACE2 receptor. It is notable to mention that changes in this spike protein segment may result in the virus becoming more contagious and spreading more easily between people. Britain on 20 December has alerted the World Health Organization that the new strain identified is the likely cause of the surge in infections of London's cases [26,27]. On 19 December 2020, due to the increase of this new virus, the UK ordered the new rules to be done from 20 December and over the coming weeks for affected areas going into a 'Tier 4' level with movement limitations within among affected areas [26,27]. It was picked up via the COVID-19 Genomics UK (COG-UK) consortium, which undertakes random genetic sequencing of positive COVID19 samples around the UK.

The studies about this new virus's behavior are ongoing, and poorer clinical reports, mortality, and especially the number of affected groups have not been reported to date. As mentioned, this recent virus in the UK is known as VUI 202012/01 and is defined through several spike mutations (deletion 69-70 and144 amino acids, and also deletion of N501Y, A570D, D614G, P681H, T716I, S982A, D1118H domains) as well as mutations in other parts of genomic sections (Scheme 1) [28]. N501Y mutation is placed in the receptor-binding domain and is related to the Next strain clade 20B [GISAID clade GR [29], and B.1.1.7 [29,30], respectively. Phylogenetic analysis shows that several intermediary forms exist among these variants. In addition, these clusters differ via 30 nucleotide substitutions inside coronaviruses per genome per month has created.

The UK has organized the virus genome data bank called COG-UK and contains national public health institutes, national Health organizations, and academic institutions. They attempt to keep and control the sequencing coverage geographically and keep the turnaround time's low [30]. The abnormal large numbers of spikes, genetic mutations, other protein properties of the species virus in the UK confirm that these kinds of viruses have not emerged through a gradual accumulation of mutations in the UK.

Those are also unlikely that have arisen via ongoing vaccination schedules as the observed increase does not match the timing of such activities[31]. One probable guess for the appearance of these mutations is prolonged COVID-19 infection in a patient that viruses are able to reform their structures in a wide range of time. With reduced immune competence, a prolonged infection can lead to the accumulation of immune escape mutations at an elevated rate [32]. Another probable guess could be a consistent phenomenon in a virus that appears in a different animal and is then transmitted back to humans. Some of the essential and statistical 
numbers, such as R0 or number of mortality, are important for public health response planning but are not possible to remove pandemic disease in the estimation Process. Although the diversity among pandemic COVID-19 sequences is not too much, its fast spread makes the virus's natural selection opportunity to act favorable mutations. This is the same as the influenza issue, where mutations slowly accumulate in the hemagglutinin protein during a flu season, and there are complex interactions among the amino acids that can confer immune resistance to the virus $[32,33]$. Various spike mutations have been produced through mink (described in the Netherlands) [34]. Finally, the variants have probably emerged via circulation in countries with no or very low sequencing coverage. These cases were predominantly in England's southeast, but there have been recent reports from further afield, including Wales and Scotland. Nick Loman [28], a researcher of genomics at the University of Birmingham, explained a briefing by the Science Media Centre on 15 December that the mutations viruses were first spotted in late September and now accounts for $25 \%$ of viruses sequenced in Norfolk, $15 \%$ in Essex, and 5\% in Suffolk. There is no data to confirm that it had been imported from abroad basically, so it is probably to have evolved in the UK [28,35]. Due to the speed of this new virus spreads, it would be hard to keep it under control until we have the vaccine done. Longer seasonal epidemics allow selection pressure to continue over a more extended period, enhancing virus development opportunities with novel antigenic surfaces that resist preexisting immunity [36, 37]. Matt Hancock told the House of Commons on 14 December that initial analysis showed that the new variant "may be associated" with the recent rise in southeast England cases. However, this is not the same as saying that it is causing the rise. Loman explained, "This variant is strongly associated with where we are seeing increasing rates of COVID-19. The mentioned situation is a harmonic combination, but we can't say it is the root, so researchers are worried about that, and it needs urgent follow-up and investigation. This virus is new to scientists and they do not yet know if it will wane seasonally as the weather warms and humidity increases, but our lack of pre-existing immunity and its high transmissibility compared with influenza are among the reasons it may not. If the pandemic increases time by time, this could enhance antigenic problems and accumulate people due to immunological mutations during the year or more it will take to deliver the first vaccine. By considering this problem, we might be able to avert missing control in the virus that, if ignored, could ultimately limit the effectiveness of the first vaccines to clinical use. Therefore, there is an urgent need to provide an effective vaccine against COVID-19 and antibodies as soon as possible [38]. Virus mutations are not strange, and researchers have already found a few thousands of different coronavirus mutations. However, most of these mutations do not affect how easily the virus spreads or the severity of the symptoms. Last month, several million mink were discovered to be carrying a kind of COVID-19. When the UK's new strain was first detected, health officials thought whether the virus's fast spread was due to widespread carelessness or the contagiousness of the strain itself. After further research, they found that the new strain is, in fact, significantly more transmissible. However, researchers don't believe the variant leads to an increase in severe illness or more serious side effects. Researchers are still evaluating whether the strain will be more or less receptive to the currently rolled vaccines. Although health authorities have said no formal conclusions have been made, it is unlikely that the mutation would hinder the vaccines' effectiveness. Over the last few weeks, the UK has faced a rapid increase in COVID-19. 

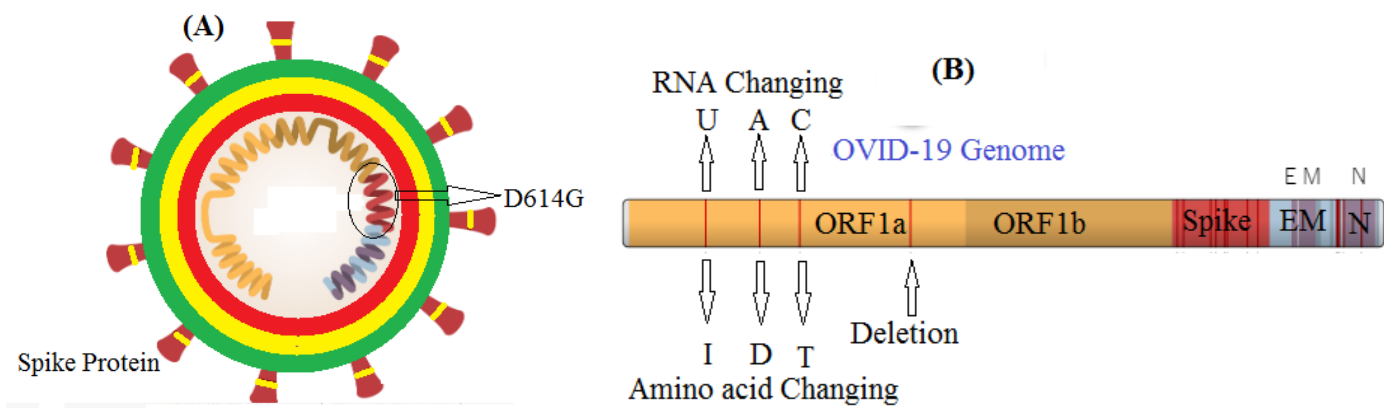

Scheme 1. New coronavirus variant; (A): D614G Mutation (B): mRNA and protein changing in D614 mutation.

This increase was pronounced in South East England, with an increase in the 14-day case. Analysis of UK- COVID-19 VUI 202012/01 using viral genome sequence data a large confirmed a proportion higher than fifty percent of cases that belonged to a new single phylogenic cluster [39]. Overall, less than 10 percent of all COVID-19 cases are regularly sequenced in the UK, with sequencing in Kent and South East England, which was most affected, around four percent. As of 13 December 2020, 1108 individuals had been identified with this virus variant in England, with the earliest case identified from 20 September 2020 [26-28]. The application of vaccine approaches against COVID-19 targets the trimeric spike protein (S) to elicit protective neutralizing antibodies that causes the spike to mediate binding and entry into host cells [40]. Each Spike segment contains an N-terminal S1 domain (Scheme 1) and a membrane-proximal $S 2$ domain that mediates receptor binding and membrane fusion, respectively [41]. The main segment of a virus is a long RNA, and obviously, each mutation arises naturally as the virus replicates.

Although several thousands of mutations have already arisen from mRNA sections, only a small minority is likely to be important and change the virus appreciably. COG-UK says that around four thousand mutations appear in the spike segment, and Mutations are expected and are a natural part of evolution [26-28]. All immunogens and testing materials are usually based on the Spike protein sequence from Wuhan's index strain [40]. This recent virus is closely related to SARS; the two viruses share $\sim 80 \%$ sequence identity [20], and both use angiotensinconverting enzyme-2 (ACE2) as their cellular receptor [19]. However, the S-protein has a higher affinity for ACE2 than the SARS-CoV's corresponding S-protein [41]. It must be seen to what extent experience learned from SARS help formulate hypotheses about coronavirus, but SARS studies suggest that the nature of the antibody responses to the Spike protein are complex. It is unknown yet that mutations that make viruses more infectious don't necessarily make them more dangerous. As an instance, the D614G variant is believed to have increased the virus's ability to be transmitted and is now the most common type circulating in the UK, although it doesn't seem to result in more severe disease. Public Health England's laboratory is currently working to find any evidence that the new variant increases or decreases disease severity. The new variant has mutations to the spike protein that the three leading vaccines are targeting. However, vaccines produce antibodies against many regions in the spike protein, so it's unlikely that a single change would make the vaccine less effective. Over time, as more mutations occur, the vaccine might need to be altered. The coronavirus doesn't mutate as quickly as the flu virus, and the vaccines that have so far proved effective in trials are types that can easily be tweaked if necessary. 


\section{Materials and Methods}

\subsection{Docking studies of several mutations.}

Via looking for the bounded structures of some ligands, they can be select via the check box of a ligand. By this work, the iGEMDOCK has been applied. Through this software, the acceptable receptor can be defined for the binding site in whole protein structures. The protein composition is worked with a ligand, and iGEMDOCK can help to define the suitable binding site quickly. If the co-crystallized ligands are retained on the binding site structures, it will be predicted poses. Cluster analysis is the partitioning of a data set into subsets. The data in each ideal subset will share some common trait, iGEMDOCK clusters the ligands based on interaction and atomic composition features. Interaction feature is extracted from the proteinligand interactions, and atomic composition is accounted for atomic types in different functional groups. Following steps have been done in docking simulation :(a) prepare the binding site on the protein-ligand; (b) browsing and selecting the protein file; (c) defining the binding site type as a bounded ligand; (d) defining the center of the binding site by selected ligand; (e) setting the size of the binding site through the extended radius from the selected ligand. IGEMDOCK yields an analysis surrounding visualized tools and post-analysis tools for users, which can visualize the docked states, and categories through the protein-ligand interactions. Consequently, the prediction and scores of ligands can be saved in the output path. The minimum energy poses of each ligand will be outputted into the "best: Pose" location. These analysis tools are premeditated based on the analysis of those poses. You are able to specify the number of the cluster for your data or adjust the number by the preliminary clustered result. Cluster estimation is the analysis of data ranges into subsets. The information in each subset will share some general properties. These are based on interaction and atomic combination aspects. Interaction aspects are extracted from the protein-ligand couples, and atomic combinations are calculated atomic types in various functional groups. Based on Mootha et al. works, Genotyping of the exon 35 mutation has been simulated for clearing the mechanism of mutation in Cyt $c$, Figure 3. Mootha et al. exhibited a mutation that was performed by primer extension of PCR and then detected by matrix-assisted laser desorption ionization. PCR products were purified using the shrimp alkaline phosphatase method and extended by adding a homogeneous Mass-Extend primer as per the Sequencer- Mass-Array protocol. We investigated our model with a wide range of mega-based regions of that genome containing several definite genes and some other unknown genes through translation and expression data of m- RNA. The results are confirmed with experimental data. As improvement genes with higher-density m-RNA expression and more comprehensive protein-membrane interaction become available, it should apply such analysis widely.

\subsubsection{Molecular modeling.}

The 3-D protein region from AA 591 to 710 was modeled using I-TASSER multiple template threading methodology in the Nova Fold application software available from DNASTAR Inc., Madison, WI. The highest Tm-Score models for D614 or G614 were aligned using Pymol available from Schrodinger, New York, NY. Residues surrounding the cleavage site are identified using the nomenclature of Schechter and Berger. Distances between atoms were calculated using Pymol distance measurement. 


\subsubsection{Variant mutations.}

(1): SARS-CoV-2 SP RBD, E484K, K417N, N501Y; 2019-nCoV SP RBD, E484K, K417N, N501Y, or SARS-CoV-2, also known as 2019-nCoV (2019 Novel coronavirus), is a virus that causes illnesses ranging from the common cold to severe diseases. SARS-CoV-2 Spike Protein is composed of $\mathrm{S}_{1}$ domains and $\mathrm{S}_{2}$ domains. Moreover, SARS-CoV-2 Spike protein (RBD, E484K, K417N, N501Y, His \& Avi Tag) carries polyhistidine and Avi tags at the C-terminus.

(2) SARS-CoV-2 Spike protein (RBD, N501Y, His \& Avi Tag) can bind with human ACE2 (Cat. No. Z03484) in functional ELISA assay.

(3) SARS-CoV-2 SP RBD, N439K; 2019-nCoV SP RBD, N439K, The spike protein mutation N439K may help the virus escape the host's immune response. SARS-CoV-2 Spike protein (RBD, N439K, His \& Avi Tag) carries polyhistidine and Avi tags at the C-terminus

(4) SARS-CoV-2 S1 protein, K417N; 2019-nCoV S1 protein, K417N, SARS-CoV-2 Spike protein (S1, K417N, His Tag) carries a polyhistidine tag at the C-terminus. (Fig.1).

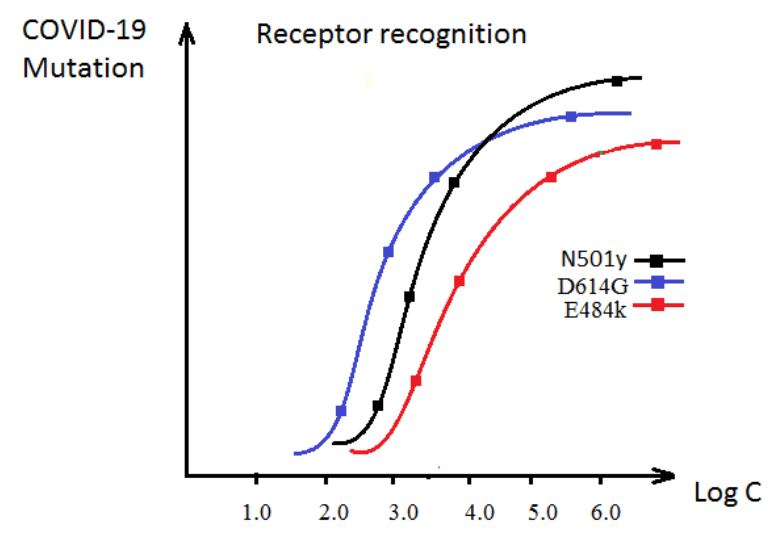

Figure 1. Comparison of three corona virus Mutation

\section{Results and Discussion}

\subsection{D614G stabilizing mutations.}

We modeled, simulated, analyzed, and calculated our system based on our previous works [42-96].

The mutation D614G was identified in the Spike mutation report in early March and was accompanied by two other mutations: a silent C-to-T mutation in the nsp3 gene and a Cto-T mutation, which results in an RNA-dependent RNA polymerase ( $\mathrm{RdRp}$ ) amino acid change (RdRp P323L) (Figure 2) [97].

\subsection{The complex of mutant V599E B-RAF and BAY439006.}

The segment of V599EB-RAF kinase domains in structure with the RAF inhibitor BAY43-9006 show that the activation domain is kept in an inactive situation through association with the P loop. The clustering of most mutations suggests that disruption of this interaction converts B-RAF into its active conformation (Figure 3) [98]. Nowadays, a new SAR-CoV-2 appeared in the England that has 18 mutations that contain 8 mutations in spike and the other in several membrane proteins. Spike mutations have also appeared during transfers of virus from humans to humans and humans to animals [99]. 


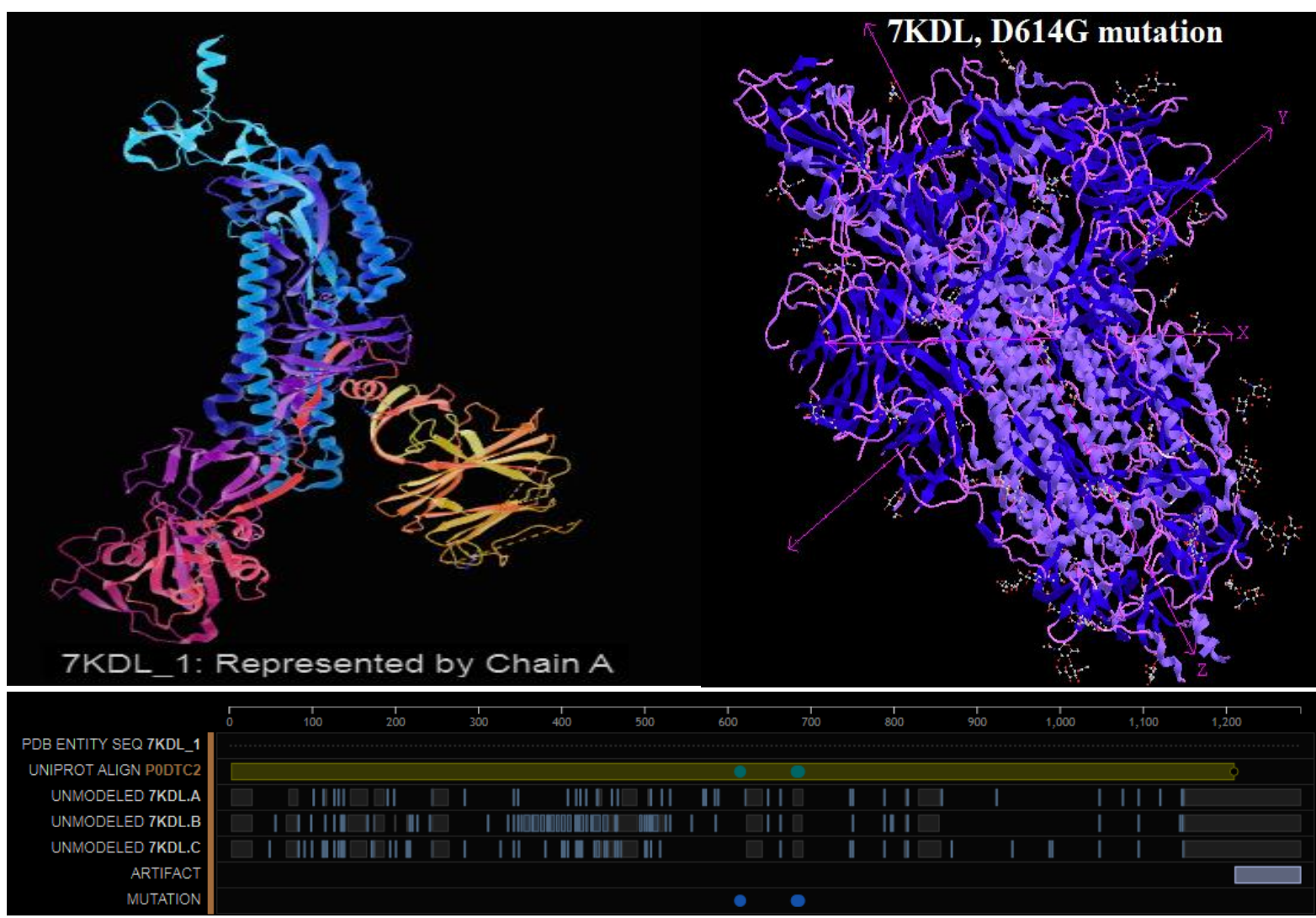

Figure 2. D614G 1-RBD up Spike Protein Trimer without the P986-P987 stabilizing mutations (S-GSASD614G).

The mutations that have occurred to date in the corona virus spike during human-tohuman transmission and following human-to-animal passage have several commonly occurring natural features of coronavirus spike evolution that may be involved in interspecies transfers that is listed as:

hCoV-19/SouthAfrica/Tygerberg-461/2020|EPI_ISL_745186|2020-12-07;hCoV19/England/LOND-1267020/2020|EPI_ISL_741243|2020-12-11; hCoV- 19/mouse/Harbin/ HRB-26m/2020|EPI_ISL_459910|2020-04-19;hCoV-19/mink/Netherlands/1/2020 EPI_ISL_ 431778, 2020-04-24;hCoV-19/mink/Netherlands /NB0102KS/2020|EPI_ISL_447624 2020 04-29;hCoV-19/mink/Netherlands/NB02_07KS/2020,EPI_ISL_447629 |2020-04-29;hCoV19/mink/Netherlands /NB02_16RS/2020|EPI_ISL_447632|2020-04-28;hCoV-19/cat/France /Env-Ba/2020|EPI_ISL_483063|2020-05-14; hCoV-19/cat/France/Env- Di/2020| EPI_ISL_ 483064| 2020-05-14hCoV-19/cat/Belgium/BE-MG-320/2020 |EPI_ISL_487275|2020-0311;hCoV-19/cat/Denmark/mDK-315 /2020|EPI_ISL_683164|2020-11-17; hCoV-19/cat/USA /TX-TAMU-013/2020|EPI_ISL_699506|2020-06-28hCoV-19/cat/USA/TX-TAMU-57/2020| EPI_ISL_699507|2020-07-17;hCoV-19/cat/USA/TX-TAMU-078 /2020|EPI_ISL_699509| 2020-07-29; hCoV-19/cat/Greece/2K/2020|EPI_ISL_717979|2020-11-23;hCoV-9/lion/USA / NY-3-041520/2020 |EPI_ISL_566037 |2020-04-04; hCoV-19/lion/USA/NY-041520/2020 |EPI_ ISL_566038|2020-04-04;hCoV-19/lion/USA/NY-2/2020|EPI_ISL_566044|2020-0404;hCoV-19/tiger/USA/ NY-040420/2020|EPI_ISL_420293|2020-04-02; hCoV- 19/dog/ HongKong/ 20-02756/2020 |EPI_ISL_414518 |2020-02-26; hCoV-19/dog/USA/TX-TAMU077/2020|EPI_ISL_699508|2020-07-28; hCoV-19/dog/Italy/ Dog399-20BA /2020 EPI_ISL_ 730652,2020-11-04 [99,100]. 


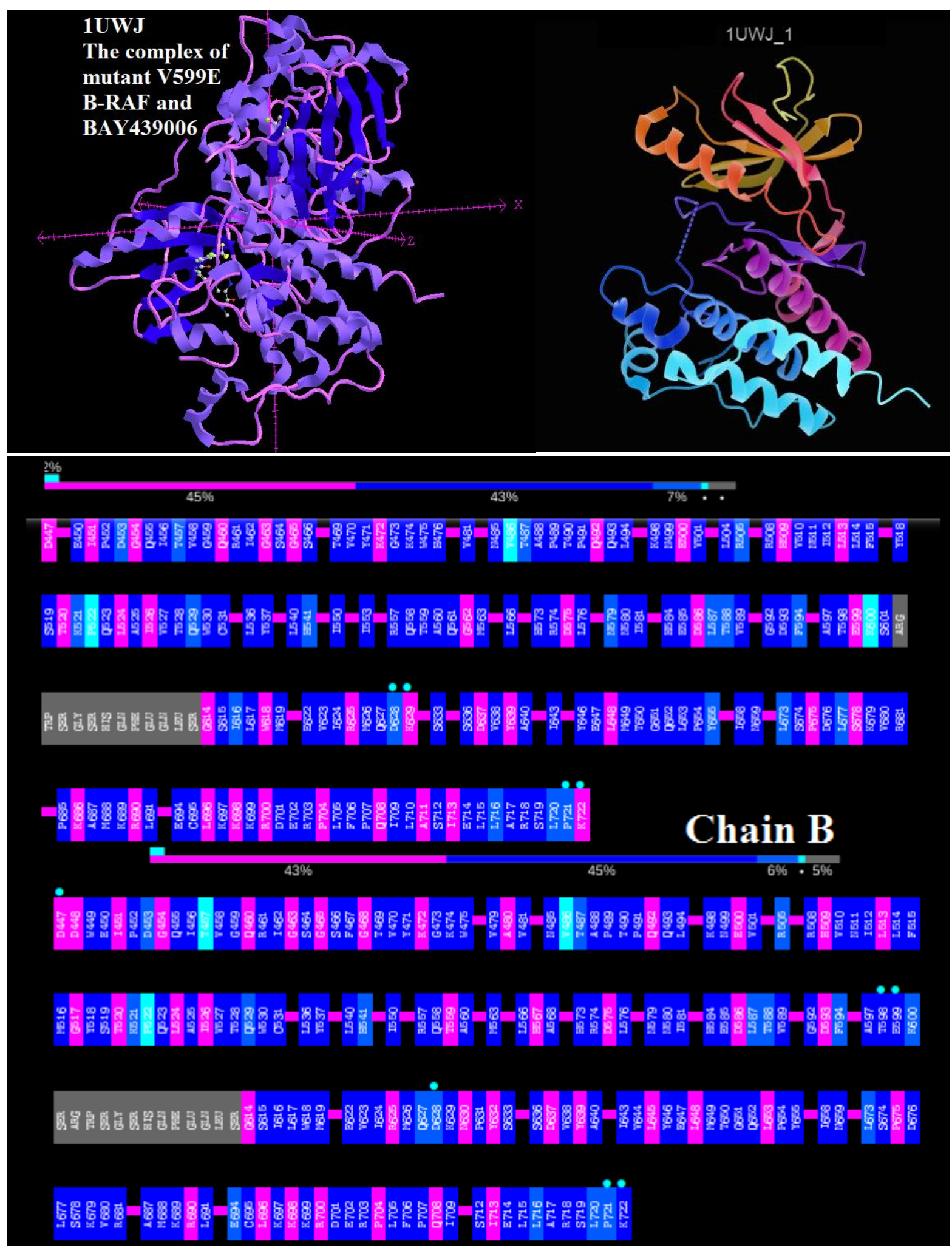

Figure 3. The complex of mutant V599E B-RAF and BAY439006.

\subsection{Spike protein mutation $N 501 Y$.}

The mutational analyses revealed a total of around a thousand unique amino acid substitutions distributed across many SARS-CoV2 S protein positions. Among these positions, most of them are located in the primary structure of the $S$ protein. The position-specific variability of $S$ protein was visualized in VMD visualization. N501Y mutation was mainly observed in the UK during the last weeks, which led to new restrictions, and many countries closed their borders for travelers from the island. A little is known about the N501Y, but its 
position and well-established interaction with the human ACE2 protein responsible for the virus-cell entry deserve special attention. Moreover, it has been shown that N501Y significantly increases virus adaption in a mouse model (Figure 4).
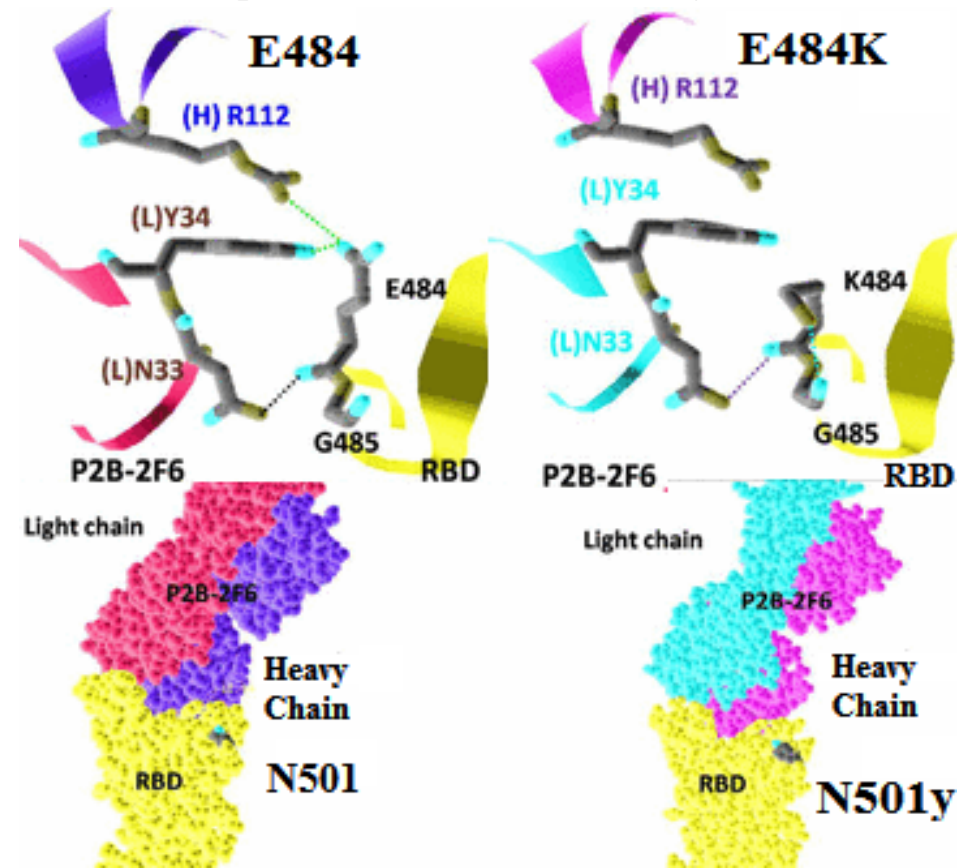

Figure 4. Intra \& intermolecular H-bonding involving the Wuhan strain and E484K mutant of corona virus spike protein receptor-binding domain in complex with P2B-2F6 neutralizing antibody, including spike protein RBD, heavy chain $(\mathrm{H})$, and light chains $(\mathrm{L})$ of the P2B-2F6 neutralizing.

\section{Conclusions}

The mutated coronavirus that occurs is highly more transmissible than the original and has raised the alarm in the UK and worldwide. Although it seems this disease is serious, by vaccines it can protect the human against it. Based on the mathematical simulation, the coronavirus Genomics UK consortium calculations predict that B.1.1.7 might be up to 75 percent more transmissible than the original virus. "It's a shocking valuation, says Ali Mokdad, a population health expert at the University of Washington. This is a stubborn and opportunistic virus." However, some scientists doubt that this variant's fast spread in the UK necessarily means it is more transmissible. However, until we have some data, we must really be careful concerning what we do, and the best information on transmissibility will come from knowledge of related animals. The best data on transmissibility will come from animals' behavior that looks at whether this virus moves more easily from one creature to another or not. Michael Farzan, an immunologist at the Scripps Research Institute, believes that the N501Y mutation appears to have appeared independently several times in other geographical areas are further. Other spike protein mutations, including one called D614G that have been seen in the US, allow the virus to replicate better in mice's upper respiratory tract rather than the lower tract.

\section{Funding}

This research received no external funding.

\section{Acknowledgments}

This research has no acknowledgments. 


\section{Conflicts of Interest}

\section{The authors declare no conflict of interest.}

\section{References}

1. Lana, R.M.; Coelho, F.C.; Gomes, M.F.d.C.; Cruz, O.G.; Bastos, L.S.; Villela, D.A.M.; Codeço, C.T. The novel coronavirus (SARS-CoV-2) emergency and the role of timely and effective national health surveillance. Rep Public Health 2020, http://doi.org/10.1590/0102-311X00019620.

2. Baglivo, M.; Baronio, M.; Natalini, G.; Beccari, T.; Chiurazzi, P.; Fulcheri, E.; Petralia, P.; Michelini, S.; Fiorentini, G.; Miggiano, G.; Morresi, A.; Tonini, G.; Bertelli, M. Natural small molecules as inhibitors of coronavirus lipiddependent attachment to host cells a possible strategy for reducing SARS-COV-2 infectivity? Acta Biomed 2020, 91, 161-4, https://doi.org/10.23750/abm.v91i1.9402.

3. Thomso, G. COVID-19: social distancing, ACE 2 receptors, protease inhibitors and beyond? Int J Clin Prac 2020, https://doi.org/10.1111/ijcp.13503.

4. Lippi, G.; Plebani, M. The critical role of laboratory medicine during coronavirus disease 2019, (COVID19) and other viral outbreaks. Clin Chem Lab Med 2020, https://doi.org/10.1515/cclm-2020-0240.

5. Karako, K., Song, P., Chen, Y., Tang, W. Analysis of COVID-19 infection spread in Japan based on stochastic transition model. BioSci Tre 2020. https://doi.org/10.5582/ bst. 2020. 01482.

6. Wu, A.; Peng, Y.; Huang, B.; Ding, X.; Wang, X.; Niu, P.; Meng, J.; Zhu, Z.; Zhang, Z.; Wang, J.; Sheng, J.; Quan, L.; Xia, Z.; Tan, W.; Cheng, G.; Jiang, T. Genome Composition and Divergence of the Novel Coronavirus (2019-nCoV) Originating in China. Cell Host \& Microbe 2020, 27, 325-328, https://doi.org/10.1016/j.chom.2020.02.001.

7. Cheepsattayakorn, A.; Cheepsattayakorn, R. Proximal origin and phylogenetic analysis of COVID-19 (2019nCoV or SARS-CoV-2). EC Microbiol 2020.

8. Guo, Y.R.; Cao, Q.D.; Hong, Z.S.; Tan, Y.Y.; Chen, S.D.; Jin, H.J.; Tan, K.S.; Wang, D.Y.; Yan, Y. The origin, transmission and clinical therapies on coronavirus disease 2019 (COVID-19) outbreak - an update on the status. Mil Med Res 2020, 7, https://doi.org/10.1186/s40779-020-00240-0.

9. Rothan, H.A.; Byrareddy S.N. The epidemiology and pathogenesis of coronavirus disease (COVID-19) outbreak. J Autoimm 2020, 109, https://doi.org/10.1016/j.jaut.2020.102433.

10. Koenig, K.L.; Beÿ, C.K.; McDonald, E.C. 2019-nCoV: the Identify-IsolateInform (3I) tool applied to a novel emerging coronavirus. West J Emerg Med 2020, 21, 184-90, https://dx.doi.org/10.5811\%2Fwestjem.2020.1.46760.

11. Dany, L. COVID-19: protecting health-care workers. Lancet 2020, 395, https://doi.org/10.1016/S01406736(20)30644-9.

12. McCloskey, B.; Zumla, A.; Ippolito, G.; Blumberg, L.; Arbon, P.; Cicero, A.; Endericks, T.; Lim, P.L.; Borodina, M. Mass gathering events and reducing further global spread of COVID-19: a political and public health dilemma. Lancet 2020, https://doi.org/10.1016/S0140-6736(20)30681-4.

13. Jin, Z.; Du, X.; Xu, Y.; Deng, Y.; Liu, M.; Zhao, Y.; Zhang, B.; Li, X.; Zhang, L.; Peng, C.; Duan, Y.; Yu, J.; Wang, L.; Yang, K.; Liu, F.; Jiang, R.; Yang, X.; You, T.; Liu, X.; Yang, X.; Bai, F.; Liu, H.; Liu, X.; Guddat, L.W.; Xu, W.; Xiao, G.; Qin, C.; Shi, Z.; Jiang, H.; Rao, Z.; Yang, H. Structure-based drug design, virtual screening and high-throughput screening rapidly identify antiviral leads targeting COVID-19. BioRxiv 2020, https://doi.org/10.1101/2020.02.26.964882.

14. Wu, Y.; Guo, C.; Tang, L.; Hong, Z.; Zhou, J.; Dong, X.; Yin, H.; Xiao, Q.; Tang, Y.; Qu, X.; Kuang, L.; Fang, X.; Mishra, N.; Lu, J.; Shan, H.; Jiang, G.; Huang, X. Prolonged presence of SARS-CoV-2 viral RNA in faecal samples. The Lancet Gastroenterology \& Hepatology 2020, 5, 434-435, https://doi.org/10.1016/S2468-1253(20)30083-2.

15. Mitjà, O.; Clotet, B. Use of antiviral drugs to reduce COVID-19 transmission. Lancet Glob Health 2020, 8, E638-E640, https://doi.org/10.1016/S2214-109X(20)30114-5.

16. Bashyam, A.M.; Feldman, S.R. Should patients stop their biologic treatment during the COVID-19 pandemic. Journal of Dermatological Treatment 2020, 31, 317-318, https://doi.org/10.1080/09546634.2020.1742438.

17. Cui, J.; Li, F.; Shi, Z.-L. Origin and evolution of pathogenic coronaviruses. Nature Reviews Microbiology 2019, 17, 181-192, https://doi.org/10.1038/s41579-018-0118-9.

18. Zhou, P.; Yang, X.-L.; Wang, X.-G.; Hu, B.; Zhang, L.; Zhang, W.; Si, H.-R.; Zhu, Y.; Li, B.; Huang, C.L.; Chen, H.-D.; Chen, J.; Luo, Y.; Guo, H.; Jiang, R.-D.; Liu, M.-Q.; Chen, Y.; Shen, X.-R.; Wang, X.; Zheng, X.-S.; Zhao, K.; Chen, Q.-J.; Deng, F.; Liu, L.-L.; Yan, B.; Zhan, F.-X.; Wang, Y.-Y.; Xiao, G.-F.; Shi, Z.-L. A pneumonia outbreak associated with a new coronavirus of probable bat origin. Nature 2020, 579, 270-273, https://doi.org/10.1038/s41586-020-2012-7.

19. Hoffmann, M.; Kleine-Weber, H.; Schroeder, S.; Krüger, N.; Herrler, T.; Erichsen, S.; Schiergens, T.S.; Herrler, G.; Wu, N.H.; Nitsche, A.; Müller, M.A.; Drosten, C.; Pöhlmann, S. SARS-CoV-2 Cell Entry 
Depends on ACE2 and TMPRSS2 and Is Blocked by a Clinically Proven Protease Inhibitor. Cell 2020, 181, 271-280.e278, https://doi.org/10.1016/j.cell.2020.02.052.

20. Lu, R.; Zhao, X.; Li, J.; Niu, P.; Yang, B.; Wu, H.; Wang, W.; Song, H.; Huang, B.; Zhu, N.; Bi, Y.; Ma, X.; Zhan, F.; Wang, L.; Hu, T.; Zhou, H.; Hu, Z.; Zhou, W.; Zhao, L.; Chen, J.; Meng, Y.; Wang, J.; Lin, Y.; Yuan, J.; Xie, Z.; Ma, J.; Liu, W.J.; Wang, D.; Xu, W.; Holmes, E.C.; Gao, G.F.; Wu, G.; Chen, W.; Shi, W.; Tan, W. Genomic characterisation and epidemiology of 2019 novel coronavirus: implications for virus origins and receptor binding. The Lancet 2020, 395, 565-574, https://doi.org/10.1016/S0140-6736(20)30251-8.

21. Rehman, S.U.; Shafique, L.; Ihsan, A.; Liu, Q. Evolutionary Trajectory for the Emergence of Novel Coronavirus SARS-CoV-2. Pathogens 2020, 9, 240, https://doi.org/10.3390/pathogens9030240.

22. Huang, C.-L., et al. (2020). A pneumonia outbreak associated with a new coronavirus of probable bat origin. Nature 579, 270-273.

23. The Brussels Times. Netherlands bans flights from UK over new Covid mutation [20 December, 2020 ]. Available from: https://www.brusselstimes.com/news/belgium-all-news/146288/netherlands-bans-flights from-uk-over-new-covid-mutation-found-coronavirus-van-ranst-who/.

24. van Dorp L, Richard D, Tan CCS, Shaw LP, Acman M, Balloux F. No evidence for increased transmissibility from recurrent mutations in SARS-CoV-2. Nature communications. 2020 Nov 25;11(1):5986.

25. Volz E, Hill V, McCrone JT, Price A, Jorgensen D, O’Toole Á, et al. Evaluating the Effects of SARS-CoV2 Spike Mutation D614G on Transmissibility and Pathogenicity. Cell. 2020 2020/11/19/.

26. GOV.UK. Speech: Prime Minister's statement on coronavirus (COVID-19): 19 December 2020 [20 December, 2020]. Available from: https://www.gov.uk/government/speeches/prime-ministers-statement-oncoronaviruscovid-19-19-december-2020.

27. GOV.UK. Guidance: Full list of local restriction tiers by area. [20 December, 2020]. Available from: https://www.gov.uk/guidance/full-list-of-local-restriction-tiers-by-area.

28. Rambaut, A.; Loman, N.; Pybus, O.; Barclay, W.; Barrett, J.; Carabelli, A.; Connor, T.R.; Peacock, T.; Robertson, D.L.; and Volz, E. Preliminary genomic characterisation of an emergent SARS-CoV-2 lineage in the UK defined by a novel set of spike mutations, 2020. Available online: https://virological.org/t/ preliminary-genomic-characterisation-of-an-emergent-sars-cov-2-lineage-in-the-uk-defined-by-a-novel-setof-spike-mutations/563.

29. Shu, Y.; McCauley, J.; GISAID: Global initiative on sharing all influenza data - from vision to reality. Euro Surveill. 2017;22(13):30494.

30. Hodcroft, E.; Neher, R.; Phylogenetic analysis of SARS-CoV-2 clusters in their international context - cluster S.N501 [Internet]. Nextstrain; 2020 [updated 15 December 2020; cited 17 December 2020]. Available from: https://nextstrain.org/groups/neherlab/ncov/S.N501?c=gt-S_69,501\&m=div.

31. Choi, B.; Choudhary, M.C.; Regan, J.; Sparks, J.A.; Padera, R.F.; Qiu, X.; et al. Persistence and Evolution of SARS-CoV-2 in an Immunocompromised Host. New England Journal of Medicine. 2020;383(23):2291-3.

32. McCarthy K.R.; Rennick, L.J.; Nambulli, S.; Robinson-McCarthy, L.R.; Bain, W.G.; Haidar, G.; et al. Natural deletions in the SARS-CoV-2 spike glycoprotein drive antibody escape. bioRxiv. 2020:2020.11.19.389916.

33. Lv, M.; Luo, X.; Estill, J.; Liu, Y.; Ren, M.; Wang, J.; Wang, Q.; Zhao, S.; Wang, X.; Yang, S.; Feng, X.; Li, W.; Liu, E.; Zhang, X.; Wang. L.; Zhou, Q.; Meng, W.; Qi, X.; Xun, Y.; Yu, X.; Chen, Y. Coronavirus disease (COVID-19): a scoping review. Euro Surveill 2020, 25, 2000125, https://doi.org/10.2807/15607917.ES.2020.25.15.2000125.

34. Oude Munnink, B.B.; Sikkema, R.S.; Nieuwenhuijse, D.F.; Molenaar, R.J.; Munger, E.; Molenkamp, R.; et al. Transmission of SARS-CoV-2 on mink farms between humans and mink and back to humans. Science. 2020:eabe5901.

35. Wu, A.; Peng, Y.; Huang, B.; Ding, X.; Wang, X.; Niu, P.; Meng, J.; Zhu, Z.; Zhang, Z.; Wang, J.; Sheng, J.; Quan, L.; Xia, Z.; Tan, W.; Cheng, G.; Jiang, T. Genome Composition and Divergence of the Novel Coronavirus (2019-nCoV) Originating in China. Cell Host Microbe 2020, 27, 325-328, https://doi.org/10.1016/j.chom.2020.02.001.

36. Chattopadhyay, I.; Kiciman, E.; Elliott, J.W.; Shaman, J.L.; Rzhetsky, A. Conjunction of factors triggering waves of seasonal influenza. eLife 2018, 7, https://doi.org/10.7554/eLife.30756.

37. Boni, M.F.; Gog, J.R.; Andreasen, V.; Feldman, M.W. Epidemic dynamics and antigenic evolution in a single season of influenza A. Proceedings. Biological sciences 2006, 273, 1307-1316, https://doi.org/10.1098/rspb.2006.3466. 
38. Venkat Kumar, G.; Jeyanthi, V.; Ramakrishnan, S. A short review on antibody therapy for COVID-19. New Microbes and New Infections 2020, 35, 100682, https://doi.org/10.1016/j.nmni.2020.100682.

39. Chen, W.H.; Hotez, P.J.; Bottazzi, M.E. Potential for developing a SARS-CoV receptor-binding domain (RBD) recombinant protein as a heterologous human vaccine against coronavirus infectious disease (COVID)-19. Hum. Vaccin. Immunother. $\mathbf{2 0 2 0 ,}$ 16, https://doi.org/10.1080/21645515.2020.1740560.

40. Wang, C.; Li, W.; Drabek, D.; Okba, N.M.A.; van Haperen, R.; Osterhaus, A.D.M.E.; van Kuppeveld, F.J.M.; Haagmans, B.L.; Grosveld, F.; Bosch, B.-J. A human monoclonal antibody blocking SARS-CoV-2 infection. bioRxiv 2020, https://doi.org/10.1101/2020.03.11.987958.

41. Wrapp, D.; Wang, N.; Corbett, K.S.; Goldsmith, J.A.; Hsieh, C.-L.; Abiona, O.; Graham, B.S.; McLellan, J.S. Cryo-EM structure of the 2019-nCoV spike in the prefusion conformation. Science 2020, 367, 1260, https://doi.org/10.1126/science.abb2507.

42. Mollaamin, F.; Monajjemi, M. DFT outlook of solvent effect on function of nano bioorganic drugs. Phys. Chem. Liq. 2012, 50, 596-604, https://doi.org/10.1080/00319104.2011.646444.

43. Mollaamin, F.; Gharibe, S.; Monajjemi, M. Synthesis of various nano and micro ZnSe morphologies by using hydrothermal method. International Journal of the Physical Sciences 2011, 6, 1496-1500.

44. Monajjemi, M. Graphene/(h-BN) n/X-doped graphene as anode material in lithium ion batteries $(\mathrm{X}=\mathrm{Li}, \mathrm{Be}$, $\mathrm{B}$ and N). Macedonian Journal of Chemistry and Chemical Engineering 2017, 36, 101-118, http://dx.doi.org/10.20450/mjcce.2017.1134.

45. Monajjemi, M. Cell membrane causes the lipid bilayers to behave as variable capacitors: A resonance with self-induction of helical proteins. Biophys. Chem. 2015, 207, 114-127, https://doi.org/10.1016/j.bpc.2015.10.003.

46. Monajjemi, M. Study of CD5+ Ions and Deuterated Variants $(\mathrm{CHxD}(5-\mathrm{x})+)$ : An Artefactual Rotation. Russian Journal of Physical Chemistry A 2018, 92, 2215-2226, https://doi.org/10.1134/S0036024418110286.

47. Monajjemi, M. Liquid-phase exfoliation (LPE) of graphite towards graphene: An ab initio study. J. Mol. Liq. 2017, 230, 461-472, https://doi.org/10.1016/j.molliq.2017.01.044.

48. Jalilian, H.; Monajjemi, M. Capacitor simulation including of $\mathrm{X}$-doped graphene $(\mathrm{X}=\mathrm{Li}, \mathrm{Be}, \mathrm{B})$ as two electrodes and $(\mathrm{h}-\mathrm{BN}) \mathrm{m}(\mathrm{m}=1-4)$ as the insulator. Jpn. J. Appl. Phys. 2015, 54, 085101, https://doi.org/10.7567/jjap.54.085101.

49. Ardalan, T.; Ardalan, P.; Monajjemi, M. Nano Theoretical Study of a C16 Cluster as a Novel Material for Vitamin C Carrier. Fullerenes, Nanotubes and Carbon Nanostructures 2014, 22, 687-708, https://doi.org/10.1080/1536383X.2012.717561.

50. Mahdavian, L.; Monajjemi, M.; Mangkorntong, N. Sensor Response to Alcohol and Chemical Mechanism of Carbon Nanotube Gas Sensors. Fullerenes, Nanotubes and Carbon Nanostructures 2009, 17, 484-495, https://doi.org/10.1080/15363830903130044.

51. Monajjemi, M.; Najafpour, J. Charge Density Discrepancy Between NBO and QTAIM in Single-wall Armchair Carbon Nanotubes. Fullerenes, Nanotubes and Carbon Nanostructures 2014, 22, 575-594, https://doi.org/10.1080/1536383X.2012.702161.

52. Monajjemi, M.; Seyed Hosseini, M. Non Bonded Interaction of B16N16 Nano Ring with Copper Cations in Point of Crystal Fields. Journal of Computational and Theoretical Nanoscience 2013, 10, 2473-2477, https://doi.org/10.1166/jctn.2013.3233.

53. Monajjemi, M.; Mahdavian, L.; Mollaamin, F. Characterization of nanocrystalline silicon germanium film and nanotube in adsorption gas by Monte Carlo and Langevin dynamic simulation. Bulletin of the Chemical Society of Ethiopia 2008, 22, 277-286, https://doi.org/10.4314/bcse.v22i2.61299.

54. Lee, V.S.; Nimmanpipug, P.; Mollaamin, F.; Kungwan, N.; Thanasanvorakun, S.; Monajjemi, M. Investigation of single wall carbon nanotubes electrical properties and normal mode analysis: Dielectric effects. Russian Journal of Physical Chemistry A 2009, 83, 2288-2296, https://doi.org/10.1134/S0036024409130184.

55. Mollaamin, F.; Najafpour, J.; Ghadami, S.; Akrami, M.S.; Monajjemi, M. The electromagnetic feature of B15N15Hx (x = 0, 4, 8, 12, 16, and 20) nano rings:Quantum theory of atoms in molecules/NMR approach. Journal of Computational and Theoretical Nanoscience 2014, 11, 1290-1298.

56. Monajjemi, M.; Mahdavian, L.; Mollaamin, F.; Honarparvar, B. Thermodynamic Investigation of Enol $\leftrightarrow$ Keto Tautomerism for Alcohol Sensors Based on Carbon Nanotubes as Chemical Sensors. Fullerenes, Nanotubes and Carbon Nanostructures 2010, 18, 45-55, https://doi.org/10.1080/15363830903291564. 
57. Monajjemi, M.; Ghiasi, R.; Sadjadi, M.A.S. Metal-stabilized rare tautomers: N4 metalated cytosine $(\mathrm{M}=\mathrm{Li}+$, $\mathrm{Na}+\mathrm{K}+, \mathrm{Rb}+$ and $\mathrm{Cs}+$ ), theoretical views. Appl. Organomet. Chem. 2003, 17, 635-640, https://doi.org/10.1002/aoc.469.

58. Ilkhani, A.R.; Monajjemi, M. The pseudo Jahn-Teller effect of puckering in pentatomic unsaturated rings C4AE5, A=N, P, As, E=H, F, Cl. Computational and Theoretical Chemistry 2015, 1074, 19-25, http://dx.doi.org/10.1016\%2Fj.comptc.2015.10.006.

59. Monajjemi, M. Non-covalent attraction of $\mathrm{B} 2 \mathrm{~N}(-, 0)$ and repulsion of $\mathrm{B} 2 \mathrm{~N}(+)$ in the BnNnring: a quantum rotatory due to an external field. Theor. Chem. Acc. 2015, 134, 77, https://doi.org/10.1007/s00214-015-16689.

60. Monajjemi, M.; Naderi, F.; Mollaamin, F.; Khaleghian, M. Drug design outlook by calculation of second virial coefficient as a nano study. Journal of the Mexican Chemical Society 2012, 56, 207-211, https://doi.org/10.29356/jmcs.v56i2.323.

61. Monajjemi, M.; Bagheri, S.; Moosavi, M.S.; Moradiyeh, N.; Zakeri, M.; Attarikhasraghi, N.; Saghayimarouf, N.; Niyatzadeh, G.; Shekarkhand, M.; Khalilimofrad, M.S.; Ahmadin, H.; Ahadi, M. Symmetry Breaking of B2N(-, 0, +): An Aspect of the Electric Potential and Atomic Charges. Molecules 2015, 20, https://doi.org/10.3390/molecules201219769.

62. Monajjemi, M.; Mohammadian, N.T. S-NICS: An Aromaticity Criterion for Nano Molecules. Journal of Computational and Theoretical Nanoscience 2015, 12, 4895-4914, https://doi.org/10.1166/jctn.2015.4458.

63. Monajjemi, M.; Ketabi, S.; Hashemian Zadeh, M.; Amiri, A. Simulation of DNA bases in water: Comparison of the Monte Carlo algorithm with molecular mechanics force fields. Biochemistry (Moscow) 2006, 71, S1S8, https://doi.org/10.1134/s0006297906130013.

64. Monajjemi, M.; Lee, V.S.; Khaleghian, M.; Honarparvar, B.; Mollaamin, F. Theoretical Description of Electromagnetic Nonbonded Interactions of Radical, Cationic, and Anionic NH2BHNBHNH2 Inside of the B18N18 Nanoring. The Journal of Physical Chemistry C 2010, 114, 15315-15330, https://doi.org/10.1021/jp104274z.

65. Monajjemi, M.; Boggs, J.E. A New Generation of BnNn Rings as a Supplement to Boron Nitride Tubes and Cages. The Journal of Physical Chemistry A 2013, 117, 1670-1684, https://doi.org/10.1021/jp312073q.

66. Monajjemi, M. Non bonded interaction between $\mathrm{BnNn}$ (stator) and BN(-,0,+)B (rotor) systems: A quantum rotation in IR region. Chem. Phys. 2013, 425, 29-45, https://doi.org/10.1016/j.chemphys.2013.07.014.

67. Monajjemi, M.; Wayne, R.; Boggs, J.E. NMR contour maps as a new parameter of carboxyl's OH groups in amino acids recognition: A reason of tRNA-amino acid conjugation. Chem. Phys. 2014, 433, 1-11, https://doi.org/10.1016/j.chemphys.2014.01.017.

68. Monajjemi, M. Quantum investigation of non-bonded interaction between the B15N15 ring and BH2NBH2 (radical, cation, anion) systems: a nano molecularmotor. Struct. Chem. 2012, 23, 551-580, http://dx.doi.org/10.1007/s11224-011-9895-8.

69. Monajjemi, M. Metal-doped graphene layers composed with boron nitride-graphene as an insulator: a nanocapacitor. J. Mol. Model. 2014, 20, 2507, https://doi.org/10.1007/s00894-014-2507-y.

70. Mollaamin, F.; Monajjemi, M.; Mehrzad, J. Molecular Modeling Investigation of an Anti-cancer Agent Joint to SWCNT Using Theoretical Methods. Fullerenes, Nanotubes and Carbon Nanostructures 2014, 22, 738751, https://doi.org/10.1080/1536383X.2012.731582.

71. Monajjemi, M.; Ketabi, S.; Amiri, A. Monte Carlo simulation study of melittin: Protein folding and temperature dependence. Russian Journal of Physical Chemistry 2006, 80, S55-S62, https://doi.org/10.1134/S0036024406130103.

72. Monajjemi, M.; Heshmata, M.; Haeria, H.H. QM/MM model study on properties and structure of some antibiotics in gas phase: Comparison of energy and NMR chemical shift. Biochemistry (Moscow) 2006, 71, S113-S122, https://doi.org/10.1134/S0006297906130190.

73. Monajjemi, M.; Afsharnezhad, S.; Jaafari, M.R.; Abdolahi, T.; Nikosade, A.; Monajemi, H. NMR shielding and a thermodynamic study of the effect of environmental exposure to petrochemical solvent on DPPC, an important component of lung surfactant. Russian Journal of Physical Chemistry A 2007, 81, 1956-1963, https://doi.org/10.1134/S0036024407120096.

74. Mollaamin, F.; Noei, M.; Monajjemi, M.; Rasoolzadeh, R. Nano theoretical studies of fMET-tRNA structuren in protein synthesis of prokaryotes and its comparison with the structure of fALA-tRNA. African Journal of Microbiology Research 2011, 5, 2667-2674, https://doi.org/10.5897/AJMR11.310. 
75. Monajjemi, M.; Heshmat, M.; Haeri, H.H.; Kaveh, F. Theoretical study of vitamin properties from combined QM-MM methods: Comparison of chemical shifts and energy. Russian Journal of Physical Chemistry 2006, 80, 1061, https://doi.org/10.1134/S0036024406070119.

76. Monajjemi, M.; Chahkandi, B. Theoretical investigation of hydrogen bonding in Watson-Crick, Hoogestein and their reversed and other models: comparison and analysis for configurations of adenine-thymine base pairs in 9 models. Journal of Molecular Structure: THEOCHEM 2005, 714, 43-60, https://doi.org/10.1016/j.theochem.2004.09.048.

77. Monajjemi, M.; Honarparvar, B.; Haeri, H.H.; Heshmat, M. An ab initio quantum chemical investigation of solvent-induced effect on 14N-NQR parameters of alanine, glycine, valine, and serine using a polarizable continuum model. Russian Journal of Physical Chemistry 2006, 80, S40, https://doi.org/10.1134/S0036024406130073.

78. Monajjemi, M.; Farahani, N.; Mollaamin, F. Thermodynamic study of solvent effects on nanostructures: phosphatidylserine and phosphatidylinositol membranes. Phys. Chem. Liq. 2012, 50, 161-172, https://doi.org/10.1080/00319104.2010.527842.

79. Monajjemi, M.; Ahmadianarog, M. Carbon Nanotube as a Deliver for Sulforaphane in Broccoli Vegetable in Point of Nuclear Magnetic Resonance and Natural Bond Orbital Specifications. Journal of Computational and Theoretical Nanoscience 2014, 11, 1465-1471, https://doi.org/10.1166/jctn.2014.3519.

80. Monajjemi, M.; Ghiasi, R.; Ketabi, S.; Passdar, H.; Mollaamin, F. A Theoretical Study of Metal-Stabilised Rare Tautomers Stability: N4 Metalated Cytosine (M=Be2+, Mg2+, Ca2+, $\mathrm{Sr} 2+$ and $\mathrm{Ba} 2+)$ in Gas Phase and Different Solvents. Journal of Chemical Research 2004, 2004, 11-18, https://doi.org/10.3184/030823404323000648.

81. Monajjemi, M.; Baei, M.T.; Mollaamin, F. Quantum mechanic study of hydrogen chemisorptions on nanocluster vanadium surface. Russian Journal of Inorganic Chemistry 2008, 53, 1430-1437, https://doi.org/10.1134/S0036023608090143.

82. Mollaamin, F.; Baei, M.T.; Monajjemi, M.; Zhiani, R.; Honarparvar, B. A DFT study of hydrogen chemisorption on V (100) surfaces. Russian Journal of Physical Chemistry A, Focus on Chemistry 2008, 82, 2354-2361, https://doi.org/10.1134/S0036024408130323.

83. Monajjemi, M.; Honarparvar, B.; Nasseri, S.M.; Khaleghian, M. NQR and NMR study of hydrogen bonding interactions in anhydrous and monohydrated guanine cluster model: A computational study. J. Struct. Chem. 2009, 50, 67-77, https://doi.org/10.1007/s10947-009-0009-z.

84. Monajjemi, M.; Aghaie, H.; Naderi, F. Thermodynamic study of interaction of TSPP, CoTsPc, and FeTsPc with calf thymus DNA. Biochemistry (Moscow) 2007, 72, 652-657, https://doi.org/10.1134/S0006297907060089.

85. Monajjemi, M.; Heshmat, M.; Aghaei, H.; Ahmadi, R.; Zare, K. Solvent effect on 14N NMR shielding of glycine, serine, leucine, and threonine: Comparison between chemical shifts and energy versus dielectric constant. Bulletin of the Chemical Society of Ethiopia 2007, 21, 111-116, https://doi.org/10.4314/bcse.v21i1.61387.

86. Monajjemi, M.; Rajaeian, E.; Mollaamin, F.; Naderi, F.; Saki, S. Investigation of NMR shielding tensors in 1,3 dipolar cycloadditions: solvents dielectric effect. Phys. Chem. Liq. 2008, 46, 299-306, https://doi.org/10.1080/00319100601124369.

87. Mollaamin, F.; Varmaghani, Z.; Monajjemi, M. Dielectric effect on thermodynamic properties in vinblastine by DFT/Onsager modelling. Phys. Chem. Liq. 2011, 49, 318-336, https://doi.org/10.1080/00319100903456121.

88. Monajjemi, M.; Honaparvar, B.; Khalili Hadad, B.; Ilkhani, A.; Mollaamin, F. Thermo-Chemical Investigation and NBO Analysis of Some anxileotic as Nano- Drugs. African journal of pharmacy and pharmacology 2010, 4, 521-529.

89. Monajjemi, M.; Khaleghian, M.; Mollaamin, F. Theoretical study of the intermolecular potential energy and second virial coefficient in the mixtures of $\mathrm{CH} 4$ and $\mathrm{Kr}$ gases: a comparison with experimental data. Mol. Simul. 2010, 36, 865-870, https://doi.org/10.1080/08927022.2010.489557.

90. Monajjemi, M.; Khosravi, M.; Honarparvar, B.; Mollaamin, F. Substituent and solvent effects on the structural bioactivity and anticancer characteristic of catechin as a bioactive constituent of green tea. Int. J. Quantum Chem 2011, 111, 2771-2777, https://doi.org/10.1002/qua.22612.

91. Tahan, A.; Monajjemi, M. Solvent Dielectric Effect and Side Chain Mutation on the Structural Stability of Burkholderia cepacia Lipase Active Site: A Quantum Mechanical/Molecular Mechanics Study. Acta Biotheor. 2011, 59, 291-312, https://doi.org/10.1007/s10441-011-9137-x. 
92. Monajjemi, M.; Khaleghian, M. EPR Study of Electronic Structure of [CoF6]3-and B18N18 Nano Ring Field Effects on Octahedral Complex. J. Cluster Sci. 2011, 22, 673-692, https://doi.org/10.1007/s10876-011-04142.

93. Monajjemi, M.; Mollaamin, F. Molecular Modeling Study of Drug-DNA Combined to Single Walled Carbon Nanotube. J. Cluster Sci. 2012, 23, 259-272, https://doi.org/10.1007/s10876-011-0426-y.

94. Mollaamin, F.; Monajjemi, M. Fractal Dimension on Carbon Nanotube-Polymer Composite Materials Using Percolation Theory. Journal of Computational and Theoretical Nanoscience 2012, 9, 597-601, https://doi.org/10.1166/jctn.2012.2067.

95. Mahdavian, L.; Monajjemi, M. Alcohol sensors based on SWNT as chemical sensors: Monte Carlo and Langevin dynamics simulation. $\quad$ Microelectron. $\quad J . \quad \mathbf{2 0 1 0}, \quad 41, \quad$ 142-149, https://doi.org/10.1016/j.mejo.2010.01.011.

96. Monajjemi, M.; Falahati, M.; Mollaamin, F. Computational investigation on alcohol nanosensors in combination with carbon nanotube: a Monte Carlo and ab initio simulation. Ionics 2013, 19, 155-164, https://doi.org/10.1007/s11581-012-0708-x.

97. Gobeil, S.M.C.; Janowska, K.; McDowell, S.; Mansouri, K.; Parks, R.; Manne, K.; Stalls, V.; Kopp, M.; Henderson, R.; Edwards, R.J.; Haynes, B.F.; Acharya, P. D614G mutation alters SARS-CoV-2 spike conformational dynamics and protease cleavage susceptibility at the S1/S2 junction. bioRxiv 2020, https://doi.org/10.1101/2020.10.11.335299.

98. Wan, P.T.C.; Garnett, M.J.; Roe, S.M.; Lee, S.; Niculescu-Duvaz, D.; Good, V.M.; Project, C.G.; Jones, C.M.; Marshall, C.J.; Springer, C.J.; Barford, D.; Marais, R. Mechanism of Activation of the RAF-ERK Signaling Pathway by Oncogenic Mutations of B-RAF. Cell 2004, 116, 855-867, https://doi.org/10.1016/s0092-8674(04)00215-6.

99. Mahdy, M.A.A.; Younis, W.; Ewaida, Z. An Overview of SARS-CoV-2 and Animal Infection. Frontiers in Veterinary Science 2020, 7, 1084.

100. Robert F. Garry, Mutations arising in SARS-CoV-2 spike on sustained human-to-human transmission and human-to-animal passage, 2020. Available online: https://virological.org/t/mutations-arising-in-sars-cov-2spike-on-sustained-human-to-human-transmission-and-human-to-animal-passage/578. 